\title{
Testing of primers for the study of cyanobacterial molecular diversity by DGGE
}

\author{
C. Boutte*, S. Grubisic, P. Balthasart, A. Wilmotte \\ Center for Protein Engineering, Institute of Chemistry B6, University of Liège, B-4000, Liège, Belgium
}

Received 9 August 2005; received in revised form 27 September 2005; accepted 27 September 2005

Available online 14 November 2005

\begin{abstract}
Denaturing Gradient Gel electrophoresis (DGGE) is a PCR-based technique which is widely used in the study of microbial communities. Here, the use of the three specific 16S rRNA cyanobacterial specific primers CYA359F, CYA781R(a) and CYA781R(b) on the assessment of the molecular diversity of cyanobacterial communities is examined. Assignments of the reverse primers CYA781R(a) and CYA781R(b) with cyanobacterial strain sequences showed that the former preferentially targets filamentous cyanobacteria whereas the latter targets unicellular cyanobacteria. The influence of the GC clamp position on the forward or on reverse primer and the use of the two reverse primers separately or in equimolar mixture were investigated. Three environmental samples were subjected to amplification with 6 combinations of primers. The 6 banding patterns as well as the sequences of the bands extracted were analysed and compared. In addition, to assess the effect of the position of the GC clamp, the melting profiles of the sequences of Aphanizomenon flos-aquae PMC9707 and Synechococcus sp. MH305 were determined, with the GC clamp in the $3^{\prime}$ or $5^{\prime}$ position. Results showed that the use of two separate amplifications allowed a more complete study of the molecular diversity of the cyanobacterial community investigated. Furthermore, similar richness and identical phylogenetic assignments of extracted bands were obtained irrespective of the positioning of the GC clamp.
\end{abstract}

(C) 2005 Elsevier B.V. All rights reserved.

Keywords: 16S ribosomal RNA; Denaturating gradient gel electrophoresis; Cyanobacteria; Molecular diversity

\section{Introduction}

16S rRNA PCR-DGGE (Polymerase Chain Reaction-Denaturing Gradient Gel Electrophoresis) is one of the most frequently used technique to assess the genetic diversity of microbial communities (Muyzer, 1999; Ercolini, 2004). This method allows the separation of small DNA fragments (maximum size of $1000 \mathrm{bp}$ ) of the same length but of different sequence according to their melting properties (Nollau and Wagener, 1997).

\footnotetext{
* Corresponding author. Tel.: +32 436633 10; fax: +32 436633 64.

E-mail address: c.boutte@student.ulg.ac.be (C. Boutte).
}

Indeed, fragments with only one single base substitution can be separated with this technique (Myers et al., 1985). Typically, so as to prevent a complete denaturation of the double-stranded fragments, a GC clamp is added to the $5^{\prime}$ end of the forward primer (Myers et al., 1985; Sheffield et al., 1989; Casamayor et al., 2000; Sekiguchi et al., 2001; Lyautey et al., 2005). However, the effect of the position of this GC clamp on the forward or reverse primer on the quality of the patterns obtained has not previously been investigated.

The numbers, positions and intensities of the DGGE bands obtained can be used to determine the diversity of natural samples (Muyzer, 1999; Garcia-Pichel et al., 2003; Lyautey et al., 2005). Several biases which may 
cause pitfalls in the interpretation of the DGGE patterns have been reported, like heteroduplex formation, amplification errors, the presence of multiple copies of $16 \mathrm{~S}$ rRNA operons (Speksnijder et al., 2001; Wintzingerode et al., 1997), co-migration of different DNA fragments (Sekiguchi et al., 2001) and the presence of several melting domains in a DNA fragment (Kisand and Wikner, 2003). Nevertheless, some of these problems can be solved by the excision of the bands followed by reamplification and sequencing, as the identity of the organisms can be ascertained if the DNA fragment analysed is polymorphic.

Nübel et al. (1997) have designed the cyanobacterial primers CYA359F (forward), CYA781R(a) and CYA781R(b) (reverse) for specific amplification of a 379 bp 16S rRNA gene sequence. CYA781R(a) and CYA781R(b) differ by two polymorphic bases situated at positions 7 and $23\left(5^{\prime}\right.$ to $\left.3^{\prime}\right)$. These primers have the advantage of giving a PCR product which corresponds to variable regions V3 and V4, and contains significant information for phylogenetic assignments (Yu and Morrison, 2004). Indeed, they have been used unmodified (e.g. Casamayor et al., 2000; Garcia-Pichel et al., 2001; Abed et al., 2002; Geiß et al., 2004) or slightly adapted (Zwart et al., 2005) for numerous DGGE studies investigating cyanobacterial diversity in environmental samples.

In the present study, we aim to determine (1) the variation in the banding profiles caused by the position of the GC clamp on the forward or reverse primer, and (2) the combination of the primers designed by Nübel et al. (1997) which allows an optimum investigation of the diversity of the cyanobacterial community. To achieve this, we analysed and compared the DGGE fingerprints obtained with the six pairs of primers CYA359FGC-CYA781R(a), CYA359FGCCYA781R(b), CYA359FGC-CYA781R(a+b), CYA359F-CYA781RGC(a), CYA359F-CYA781RGC(b), CYA359F-CYA781RGC(a+b), where GC means the GC clamp. In addition, as many as possible DGGE bands were sequenced to assess the diversity of the sequences obtained.

\section{Materials and methods}

\subsection{In silico match of the reverse primers CYA781R(a) and CYA781R(b)}

Using the Probe Search tool of the software package ARB (Ludwig et al., 2004) with an alignment of 1124 cyanobacterial strain sequences, the theoretical matches of the reverse primers CYA781R(a) and CYA781R(b) were investigated.

\subsection{Sampling and DNA extraction}

Environmental samples were collected at the Eschsur-Sûre reservoir in North Luxembourg. The typical genera detected microscopically in this site during spring and summer were Anabaena, Aphanizomenon and Planktothrix. In August, populations of Limnothrix and Snowella have been reported. Woronichinia have been detected in autumn whereas no cyanobacteria have been observed during winter (Willame et al., MS in prep.).

Samples were collected by filtration of $500 \mathrm{ml}$ water on $0.2 \mu \mathrm{m}$-pore-size filters (Supor, Pall Life Science, USA). The filters were stored in $2 \mathrm{ml}$ lysis buffer (40 mM EDTA, $400 \mathrm{mM} \mathrm{NaCl}, 0.75 \mathrm{M}$ sucrose, $50 \mathrm{mM}$ Tris $\mathrm{HCl} \mathrm{pH} \mathrm{8.3)} \mathrm{(Giovannoni} \mathrm{et} \mathrm{al.,} \mathrm{1990)} \mathrm{and} \mathrm{immediately}$ frozen at $-20{ }^{\circ} \mathrm{C}$. Three environmental samples were collected for the comparison of the primer pairs, 0ES27 (04/07/2000), 0ES32 (08/08/2000) and 0ES39 (26/09/ 2000). DNA was extracted from the filters as described by Wilmotte et al. (2002) with modifications as follows. For the enzymatic lysis step, a volume of $30 \mu \mathrm{l}$ of proteinase $\mathrm{K}\left(20 \mathrm{mg} \mathrm{ml}^{-1}\right.$, MBI Fermentas, Lithuania) was used. Two milliliters of hot phenol (Sigma, USA)/chloroform/isoamylalcohol (Merck, Germany) (25:24:1) was added and incubated for $10 \mathrm{~min}$ at $56{ }^{\circ} \mathrm{C}$. During the precipitation step, nucleic acids were precipitated from the supernatant (divided in several Eppendorf tubes) by addition of two volumes of ethanol and incubated for two hours at $-20{ }^{\circ} \mathrm{C}$. The tubes were centrifuged for $20 \mathrm{~min}$ at $16,000 \mathrm{~g}$ and after extraction, DNA was subjected to a purification step using the PrepA-Gene DNA Purification Kit (Biorad, USA).

\subsection{PCR reactions}

As a direct amplification of the DNA with the Nübel primers gave a weak signal (data not shown), a seminested PCR reaction was performed so as to increase the sensitivity of the DGGE analysis. The 16S rRNA fragments were first amplified using the primers CYA359F and 23S30R (Taton et al., 2003). The second PCR reaction was performed with CYA359F and CYA781R(a) and/or (b), with the GC clamp on the forward or reverse primer. All the primers used are listed in Table 1 and were synthetized and purified by Gel PAGE (Polyacrylamide Gel Electrophoresis) at Eurogentec (Belgium). For the first PCR, $0.5 \mu \mathrm{l}$ of the isolated DNA was added to 49.5 $\mu \mathrm{l}$ of the amplification mixture, giving rise to final concentrations of $1 \mathrm{X}$ Super Taq Plus buffer, $1 \mathrm{mg} \mathrm{ml}^{-1}$ BSA (bovine serum albumin), $200 \mu \mathrm{M}$ dNTP mix, $0.5 \mu \mathrm{M}$ of each of the forward and reverse primers and 
Table 1

Sequences of the PCR primers used (*: 16S E. coli position, ${ }^{\#}:$ 23S E. coli position)

\begin{tabular}{|c|c|c|c|}
\hline Primer names & Position $3^{\prime}$ end & Sequence $\left(5^{\prime}-3^{\prime}\right)$ & References \\
\hline CYA359F & $359^{*}$ & ggggaattttccgcaatggg & Nübel et al., 1997 \\
\hline CYA359FGC & $359 *$ & cgccegcegegeccegegecegtccegecgeccecgeccgggggaattttccgcaatggg & Nübel et al., 1997 \\
\hline CYA784R & $784 *$ & gactacaggggtatctaatccc & derived from Nübel et al., 1997 \\
\hline CYA781R(a) & $781 *$ & gactactggggtatctaatcceatt & Nübel et al., 1997 \\
\hline CYA781RGC(a) & $781 *$ & cgccegecgegececgegecegtccegecgececcgeccgactactggggtatctaatcccatt & Nübel et al., 1997 \\
\hline CYA781R(b) & $781 *$ & gactacaggggtatctaatccettt & Nübel et al., 1997 \\
\hline CYA781RGC(b) & $781 *$ & egcecgecgegececgegecegtecegecgececegecegactacaggggtatctaatcecttt & Nübel et al., 1997 \\
\hline $23 \mathrm{~S} 30 \mathrm{R}$ & $30 \#$ & cttcgectctgtgtgectaggt & Taton et al., 2003 \\
\hline
\end{tabular}

The polymorphic bases for the primers CYA781R(a) and CYA781R (b) are in bold.

$0.8 \mathrm{U} / \mu \mathrm{l}$ of Super Taq Plus (HT Technology, UK) in a final volume of $50 \mu \mathrm{l}$. The amplification was performed using an Icycler (Bio-Rad, USA). The PCR program included 1 cycle of initial denaturation at $94{ }^{\circ} \mathrm{C}$ for $5 \mathrm{~min}$, followed by 10 cycles with a denaturing step of $45 \mathrm{~s}$ at $94{ }^{\circ} \mathrm{C}$, an annealing step of $45 \mathrm{~s}$ at $54^{\circ} \mathrm{C}$, and an elongation step of 2 $\min$ at $68^{\circ} \mathrm{C}$. The final elongation was done during $7 \mathrm{~min}$ at $68^{\circ} \mathrm{C} .0 .5 \mu \mathrm{l}$ of the first PCR product was then added to $49.5 \mu \mathrm{l}$ of the second PCR master mix (same composition as above, except for the primers used). This was performed with a combination of the forward primer CYA359F and the reverse primers CYA781R(a) and (b), separately or mixed. The GC clamp was positioned on the forward or reverse primers. We used the same PCR reagents as in the first reaction and the cycling conditions used where as described by Nübel et al. (1997), with the exception of the elongation temperature, specific of the Super Taq Plus $\left(68{ }^{\circ} \mathrm{C}\right.$ instead of $\left.72{ }^{\circ} \mathrm{C}\right)$. Reference marker prepared by PCR amplifications of DNA fragments of Cylindrospermum PCC7417, Calothrix 328, Aphanizomenon 202a and Nostoc 152 with the primers CYA359F and CYA781RGC(a) and with CYA359FCYA781RGC(b) amplifications of DNA fragments from Microcystis 130 and Synechococcus GL150636 was added in three lanes of each DGGE gel.

\section{4. $D G G E$}

The products of the second PCR reaction were analysed by DGGE. This was performed using a DCode System (Bio-Rad Laboratories, USA) with a 6\% acrylamide gel (acrylamide/bis 37.5/1) (w/v) and a denaturating gradient from $45 \%$ to $55 \%$. The $100 \%$ denaturating solution was composed of $7 \mathrm{M}$ urea and $40 \%$ formamide $(\mathrm{v} / \mathrm{v})$. The samples were prepared by adding $4 \mu \mathrm{l}$ of loading dye solution $(0.09 \%$ bromophenol blue, $0.09 \%$ xylen cyanol, $60 \%$ glycerol, $60 \mathrm{mM}$ EDTA) to $20 \mu \mathrm{l}$ of the PCR product. The electrophoresis conditions were chosen on the basis of a perpendicular gel and a time-travel experiment (data not shown). DGGE were performed at $60{ }^{\circ} \mathrm{C}$ during 999 min at a constant voltage of $45 \mathrm{~V}$. The gel was stained with $2 \mu \mathrm{l}$ Gelstar dye (BioWhittaker Molecular Applications, USA) mixed with $15 \mathrm{ml}$ of water (milli-Q). Bands were visualised under UV light and the central part of these was excised with a scalpel washed with pure ethanol. The excised acrylamide gel portion was stored in an Eppendorf tube containing $100 \mu \mathrm{l}$ of sterilized water at room temperature for 1 hour and then the tubes were stored at $-20{ }^{\circ} \mathrm{C}$. 0.5 to $1 \mu$ of supernatant was used for the reamplification reaction with CYA359F-CYA784R. The PCR products were sequenced commercially (Genome Express, France) using the CYA784R primer. The sequences of approximatively $360 \mathrm{bp}$ were submitted to a BLAST analysis, and the results are shown in Table 3 . The 36 sequences obtained have been deposited in Genbank database under the accession numbers AY646773 to AY646808.

\subsection{Analysis of the banding patterns}

Scanning of the gel was performed with a Fluor-S Max Multilmager (Bio-Rad, USA). The bands were localised using the manufacturer's software (Quantity One Software Package) on the basis of the peaks present in the densitometric curves calculated for each lane. The number of OTUs (Operational Taxonomic Units) was defined as the number of DGGE bands (Diez et al., 2001). The banding profiles were analysed using the GelCompar II Software 2.5 (Applied Maths, Belgium) after alignment with the reference marker.

\subsection{Determination of melting profiles}

The theoretical effect of the presence of the GC clamp on the forward or reverse primer was analysed using the Poland algorithm with the MELT94 software following the author's instructions (Lerman and Silverstein, 1987). This software performs the calculation of the melting profile of a known sequence, and allows the 
addition of a GC clamp of $29 \mathrm{bp}$ in $5^{\prime}$ or $3^{\prime}$ position. The 378-781 positions (based on the E. coli sequence) of the 16S rRNA of Aphanizomenon flos-aquae PMC9707 and Synechococcus sp. MH305 were used as template, to which CYA359F, CYA781R(a) or (b) primers and a GC clamp were added at the $3^{\prime}$ or $5^{\prime}$ end. These sequences correspond to the most frequent BLAST affiliations found among our sequences (six for Aphanizomenon and three for Synechococcus).

\section{Results and discussion}

\subsection{In silico match of the reverse primers CYA781R(a) and $C Y A 781 R(b)$}

Of 397 heterocystous cyanobacterial sequences, 95.2\% matched with the primer CYA781R(a) including $73 \%$ of the sequences of the genus Chroococcidiopsis, this being a sister group of the heterocystous cyanobacteria (Fewer et al., 2002) (Table 2). Concerning the non-heterocystous filamentous strains, $69.3 \%$ of the sequences matched with CYA781RGC(a). Of
381 sequences from unicellular strains, 92.6\% matched with the primer CYA781R(b), 5.0\% matched with CYA781R(a) and $2.4 \%$ did not match. Of the 46 sequences which did not match with either CYA781R(a) or (b), 11 sequences contain ambiguities, 3 contain gaps, and 32 are due to mismatches. A list of all the sequences used and their matches is available at http:// www.cip.ulg.ac.be/appendix.htm. Thus, because the polymorphism at position 23 is situated in the region critical for the specificity of annealing during PCR, the reverse primer (a) amplifies preferentially the filamentous cyanobacteria, whereas the reverse primer (b) targets mainly the unicellular cyanobacteria.

\subsection{Comparison of data when the GC clamp is on the forward or reverse primer}

For the three environmental samples 0ES27, 0ES32 and 0ES39, different DGGE patterns were obtained for the six primer combinations used, CYA359FGCCYA781R(a), CYA359FGC-CYA781R(b) CYA359FGCCYA781R(a+b), CYA359F-CYA781RGC(a), CYA359F-

Table 2

Matches for CYA781R(a) and CYA781R(b) primers with 1124 16S rRNA sequences of cyanobacterial strains examined using the Probe Search tool of the software package ARB (Ludwig et al., 2004)

\begin{tabular}{|c|c|c|c|c|c|c|c|c|c|c|c|}
\hline Heterocystous & $\begin{array}{l}\text { CYA } \\
781 R(a)\end{array}$ & $\begin{array}{l}\text { CYA } \\
781 \mathrm{R}(\mathrm{b})\end{array}$ & $\begin{array}{l}\text { No } \\
\text { match }\end{array}$ & $\begin{array}{l}\text { Filamentous } \\
\text { non-heterocystous }\end{array}$ & $\begin{array}{l}\text { CYA } \\
781 R(a)\end{array}$ & $\begin{array}{l}\text { CYA } \\
781 R(b)\end{array}$ & $\begin{array}{l}\text { No } \\
\text { match }\end{array}$ & $\begin{array}{l}\text { Unicellular } \\
\text { sensu stricto }\end{array}$ & $\begin{array}{l}\text { CYA } \\
781 R(a)\end{array}$ & $\begin{array}{l}\text { CYA } \\
781 R(b)\end{array}$ & $\begin{array}{l}\text { No } \\
\text { match }\end{array}$ \\
\hline Anabaena sp & 82 & 0 & 0 & Arthrospira sp & 4 & 1 & 0 & Acaryochloris & 0 & 3 & 0 \\
\hline Anabaenopsis sp & 4 & 0 & 0 & Geitlerinema $s p$ & 6 & 1 & 0 & Aphanocapsa sp & 0 & 1 & 1 \\
\hline Aphanizomenon $s p$ & 31 & 0 & 2 & Halospirulina $s p$ & 4 & 0 & 0 & Aphanothece sp & 0 & 2 & 0 \\
\hline Capsosira sp & 1 & 0 & 0 & Leptolyngbya sp & 0 & 20 & 3 & Chamaesiphon sp & 0 & 1 & 1 \\
\hline Calothrix sp & 8 & 0 & 2 & Limnothrix $s p$ & 2 & 3 & 0 & Cyanobium sp & 0 & 4 & 0 \\
\hline Chlorogloeopsis sp & 3 & 0 & 0 & Lyngbya sp & 9 & 0 & 3 & Cyanothece sp & 0 & 8 & 0 \\
\hline Chroococcidopsis $s p$ & 16 & 3 & 3 & Microcoleus $s p$ & 45 & 0 & 7 & Dactylococcopsis sp & 0 & 1 & 0 \\
\hline Coleodesmium $s p$ & 1 & 0 & 2 & Oscillatoria $s p$ & 24 & 36 & 6 & Dermocarpa $s p$ & 0 & 13 & 0 \\
\hline Cylindrospermopsis sp & 51 & 0 & 0 & Phormidium $s p$ & 19 & 19 & 2 & Dermocarpella $s p$ & 0 & 2 & 0 \\
\hline Cyanospira $s p$ & 0 & 0 & 1 & Planktothricoides $s p$ & 6 & 0 & 0 & Euhalothece $s p$ & 0 & 4 & 0 \\
\hline Cylindrospermum $s p$ & 4 & 0 & 0 & Planktothrix $s p$ & 85 & 1 & 0 & Gloeocapsa sp & 0 & 2 & 0 \\
\hline Fischerella $s p$ & 9 & 0 & 0 & Plectonema sp & 0 & 2 & 0 & Gloeothece sp & 0 & 4 & 0 \\
\hline Gloeobacter $s p$ & 3 & 0 & 0 & Pseudanabaena sp & 10 & 1 & 0 & Halothece sp & 0 & 1 & 0 \\
\hline Hapalosiphon $s p$ & 4 & 0 & 0 & Spirulina $s p$ & 6 & 1 & 0 & Merismopedia $s p$ & 0 & 1 & 0 \\
\hline Mastigocladopsis $s p$ & 1 & 0 & 0 & Symploca sp & 5 & 0 & 0 & Microcystis sp & 0 & 70 & 3 \\
\hline Mastigocladus sp & 2 & 0 & 0 & Trichodesmium $s p$ & 8 & 0 & 0 & Myxosarcina $s p$ & 0 & 2 & 0 \\
\hline Nodularia $s p$ & 41 & 0 & 0 & Tychonema $s p$ & 7 & 0 & 0 & Pleurocapsa sp & 0 & 6 & 0 \\
\hline Nostoc sp & 94 & 0 & 4 & Total & 240 & 85 & 21 & Prochlorococcus sp & 0 & 26 & 0 \\
\hline Nostochopsis sp & 2 & 0 & 0 & Percentage & 69.3 & 24.6 & 6.1 & Prochloron $s p$ & 0 & 2 & 0 \\
\hline Scytonema $s p$ & 4 & 0 & 2 & & & & & Prochlorothrix sp & 0 & 5 & 0 \\
\hline Spirestris sp & 3 & 0 & 0 & & & & & Staniera $s p$ & 0 & 3 & 0 \\
\hline Stigonema $s p$ & 2 & 0 & 0 & & & & & Synechococcus sp & 18 & 184 & 3 \\
\hline Symphyonema sp & 2 & 0 & 0 & & & & & Synechocystis sp & 1 & 6 & 1 \\
\hline Symphyonemopsis sp & 1 & 0 & 0 & & & & & Xenococcus sp & 0 & 2 & 0 \\
\hline Tolypothrix sp & 3 & 0 & 0 & & & & & Total & 19 & 353 & 9 \\
\hline Westiellopsis $s p$ & 6 & 0 & 0 & & & & & Percentage & 5.0 & 92.6 & 2.4 \\
\hline Total & 378 & 3 & 16 & & & & & & & & \\
\hline Percentage & 95.2 & 0.8 & 4.0 & & & & & & & & \\
\hline
\end{tabular}

The list of all sequences used for each genus and their matches are given at http://www.cip.ulg.ac.be/appendix.htm. 
CYA781RGC(b) and CYA359F-CYA781RGC(a+b).

The numbers of bands obtained for each primer pair varied (Fig. 1) and the average number of bands determined for the patterns obtained with CYA359FCYA781R(a), CYA359F-CYA781R(b) and CYA359FCYA781R $(\mathrm{a}+\mathrm{b})$ were similar whether the GC clamp was on the forward or reverse primer (6.6 and 5.0; 8.0 and $9.3 ; 7.3$ and 6.0 respectively, Fig. 1). Concerning the reamplification of the DGGE bands, a sequence could not be obtained for all band excised. Moreover, identical sequences were obtained from different bands in the same lane. This is in agreement with the observation of Nikolausz et al. (2005) that dominant amplicons could be distributed at different positions in the same pattern. If several domains have similar melting properties, stochastic effects might cause one to denaturate before the other in a fraction of the amplicon population and could also explain the presence of different bands with the same sequence in one lane.

BLAST analyses of the sequences obtained with the GC clamp on the forward and reverse primers gave the same closest relatives for samples 0ES27
(A. flos-aquae PMC9707 and PCC7905 and Synechococcus MH305), 0ES32 (A. flos-aquae PMC9707, Synechocystis PCC6803 and Synechococcus MH301) and 0ES39 (Limnothrix redekii CCAP1443/1 and Synechocystis PCC6803) (Table 3).

The differences in the banding profiles obtained with the GC clamp on the forward or reverse primer can be explained by the melting properties of the amplicons. The melting profiles obtained for the same sequence with the GC clamp on the forward or reverse primer were different whereas there was no effect with the primers CYA781R(a) and (b) even though these differ from each other by two nucleotides (Fig. 2). The modification of the melting properties could be explained by the GC content of the forward and reverse primers, $55 \%$ and $44 \%$, respectively. Thus the reverse primers had a lower melting temperature and this can be observed in Fig. 2 where the melting temperature of the DNA segment at the $3^{\prime}$ end is lower than that at the $5^{\prime}$ end, irrespective of the presence of the GC clamp. When the GC clamp is situated at the $5^{\prime}$ end, the lower melting temperature of the reverse primer CYA781R has a more pronounced

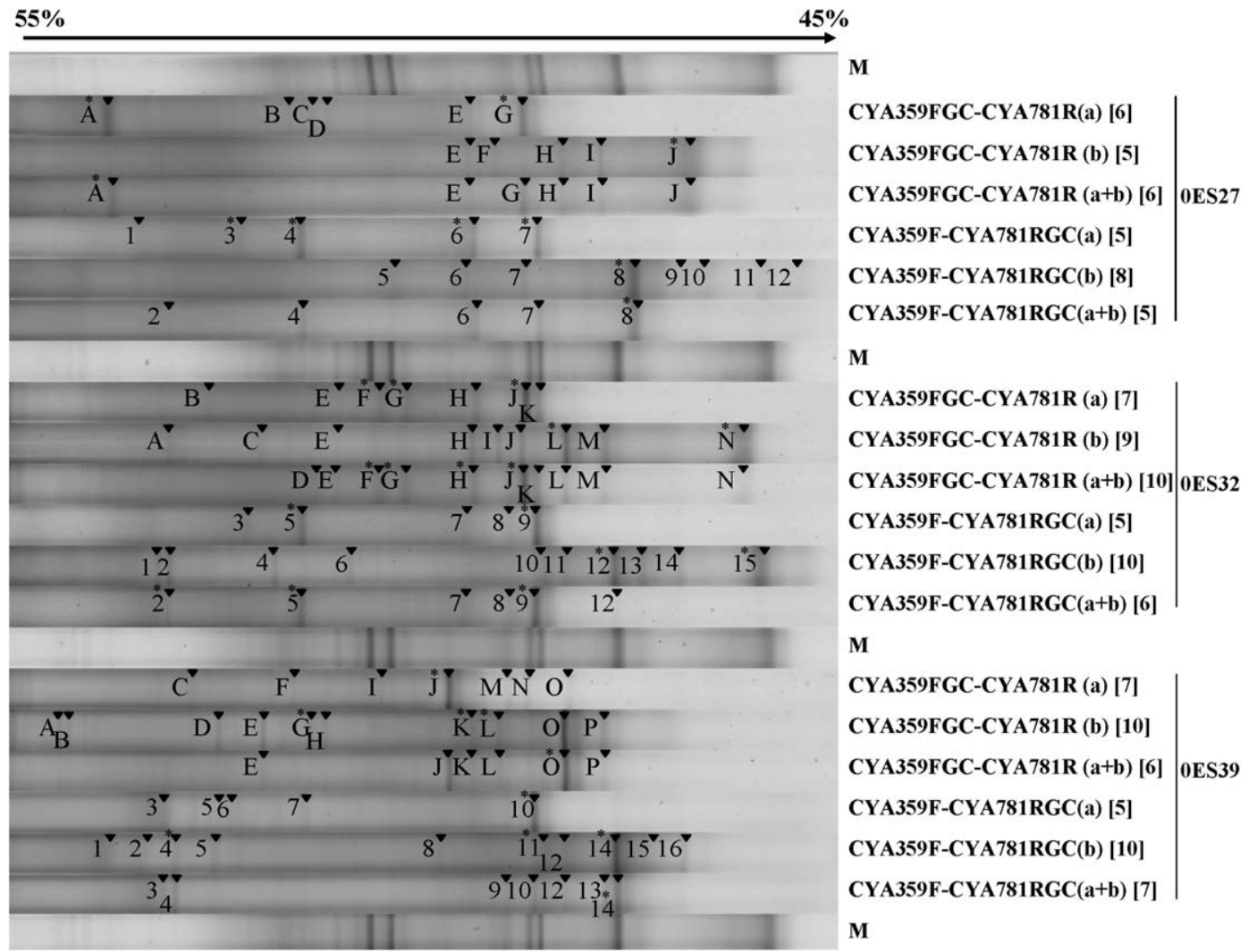

Fig. 1. DGGE patterns and designations of the bands obtained with the 6 primer pairs for samples 0ES27, 0ES32 and 0ES39. Visible bands are indicated by an arrow and bands at the same positions were given the same designation. A star indicates the bands for which a sequence was obtained. The numbers between brackets indicate the number of bands obtained for the lane. 
Table 3

Results of the BLAST analysis of the sequences obtained from the sequenced DGGE

\begin{tabular}{|c|c|c|c|c|c|}
\hline Sample & Primer pair & $\begin{array}{l}\text { Band } \\
\text { designation }\end{array}$ & $\begin{array}{l}\text { Accession } \\
\text { number }\end{array}$ & Most similar sequence & $\begin{array}{l}\text { BLAST } \\
\text { Similarity (\%) }\end{array}$ \\
\hline \multirow[t]{10}{*}{ 0ES27 } & CYA359FGC-CYA781R(a) & G & AY646774 & Aphanizomenon flos-aquae PMC9707 (AJ293130) & 100 \\
\hline & CYA359FGC-CYA781R(a) & A & AY 646775 & Aphanizomenon flos-aquae PCC7905 (AY038035) & 99 \\
\hline & CYA359FGC-CYA781R(b) & $\mathrm{J}$ & AY646776 & Synechococcus sp. MH305 (AY224198) & 99 \\
\hline & CYA359FGC-CYA781R $(\mathrm{a}+\mathrm{b})$ & A & AY646777 & Aphanizomenon flos-aquae PCC7905 & 99 \\
\hline & \multirow[t]{3}{*}{ CYA359F-CYA781RGC(a) } & 3 & AY 646778 & \multirow[t]{3}{*}{ Aphanizomenon flos-aquae PMC9707 } & \multirow[t]{3}{*}{100} \\
\hline & & 4 & AY646780 & & \\
\hline & & 7 & AY646781 & & \\
\hline & CYA359F-CYA781RGC(a) & 6 & AY646779 & Aphanizomenon flos-aquae PCC7905 & 99 \\
\hline & CYA359F-CYA781RGC(b) & 8 & AY646782 & Synechococcus sp. MH305 & 99 \\
\hline & CYA359F-CYA781RGC(a+b) & 8 & AY646783 & Synechococcus sp. MH305 & 99 \\
\hline \multirow[t]{16}{*}{ 0ES32 } & \multirow[t]{3}{*}{ CYA359FGC-CYA781R(a) } & $\mathrm{F}$ & AY646784 & \multirow[t]{3}{*}{ Aphanizomenon flos-aquae PMC9707 } & \multirow[t]{3}{*}{100} \\
\hline & & G & AY 646785 & & \\
\hline & & $\mathrm{J}$ & AY646786 & & \\
\hline & CYA359FGC-CYA781R(b) & $\mathrm{N}$ & AY646787 & Synechococcus sp. MH301 (AY224199) & 97 \\
\hline & CYA359FGC-CYA781R(b) & $\mathrm{L}$ & AY646788 & Synechocystis sp. PCC6803 (AY224195) & 94 \\
\hline & \multirow{4}{*}{ CYA359FGC-CYA781R(a+b) } & $\mathrm{F}$ & AY646789 & \multirow[t]{4}{*}{ Aphanizomenon flos-aquae PMC9707 } & \multirow[t]{4}{*}{100} \\
\hline & & G & AY646790 & & \\
\hline & & $\mathrm{H}$ & AY646791 & & \\
\hline & & $\mathrm{J}$ & AY646792 & & \\
\hline & \multirow[t]{2}{*}{ CYA359F-CYA781RGC(a) } & 5 & AY646793 & \multirow[t]{2}{*}{ Aphanizomenon flos-aquae PMC9707 } & \multirow[t]{2}{*}{100} \\
\hline & & 9 & AY646794 & & \\
\hline & CYA359F-CYA781RGC(b) & 15 & AY646795 & Synechococcus sp. MH301 & 97 \\
\hline & CYA359F-CYA781RGC(b) & 12 & AY646796 & Synechocystis sp. PCC6803 & 94 \\
\hline & \multirow[t]{3}{*}{ CYA359F-CYA781RGC(a+b) } & 2 & AY646797 & \multirow[t]{3}{*}{ Aphanizomenon flos-aquae PMC9707 } & \multirow[t]{3}{*}{100} \\
\hline & & 5 & AY646798 & & \\
\hline & & 9 & AY646799 & & \\
\hline \multirow[t]{10}{*}{ 0ES39 } & CYA359FGC-CYA781R(a) & $\mathrm{J}$ & AY646800 & Limnothrix redekei CCAP 1443/1 (AJ580007) & 99 \\
\hline & \multirow[t]{3}{*}{ CYA359FGC-CYA781R(b) } & G & AY646801 & \multirow[t]{3}{*}{ Synechocystis sp. PCC6803 } & \multirow[t]{3}{*}{94} \\
\hline & & $\mathrm{K}$ & AY646802 & & \\
\hline & & $\mathrm{L}$ & AY646803 & & \\
\hline & CYA359FGC-CYA781R(a+b) & $\mathrm{O}$ & AY646804 & Synechocystis sp. PCC6803 & 94 \\
\hline & CYA359F-CYA781RGC(a) & 10 & AY646805 & Limnothrix redekei CCAP 1443/1 & 99 \\
\hline & \multirow[t]{3}{*}{ CYA359F-CYA781RGC(b) } & 4 & AY646806 & \multirow[t]{3}{*}{ Synechocystis sp. PCC6803 } & \multirow[t]{3}{*}{94} \\
\hline & & 11 & AY646807 & & \\
\hline & & 14 & AY646808 & & \\
\hline & CYA359F-CYA781RGC(a+b) & 14 & AY646773 & Synechocystis sp. PCC6803 & 94 \\
\hline
\end{tabular}

effect, and the double-stranded DNA will melt at a lower temperature. This can also explain why the patterns produced with the GC clamp on the forward primer gave bands situated closer to the top of the DGGE gel.

Moreover, several melting domains are observed for the two sequences, irrespective of the position of the GC clamp. Ideal melting profiles are flat, and the presence of several melting domains typically results in extended (fuzzy) bands in the migration direction (Kisand and Wikner, 2003). Such fuzzy bands can be observed for the bands with sequences closely related to A. flos-aquae PMC9707 and Synechococcus sp. MH305 (0ES27: bands G, J, 4, 7, 8; 0ES32: bands H, J, 5, 9 in Fig. 1). Furthermore, the polymorphisms in high melting domains might be undetected, because the dissociation of low melting domains, which occurs earlier, strongly slows down the migration of the fragments (Fischer and Lerman, 1983; Wu et al., 1998).

\subsection{Comparison of the use of the reverse primers CYA781R(a) and CYA781R(b) used separately or together}

The lowest average number of bands observed for the DGGE patterns was obtained when using CYA781R(a) alone (5.8: Fig. 1). The primer pair CYA359FCYA781R(b) gave the highest average number of bands, irrespective of the GC clamp position (8.6) whereas the mixture of reverse primers gave an intermediate score (6.6). The diversity of bands obtained was lower when both reverse primers were used together than the sum of the bands obtained separately with the primers 

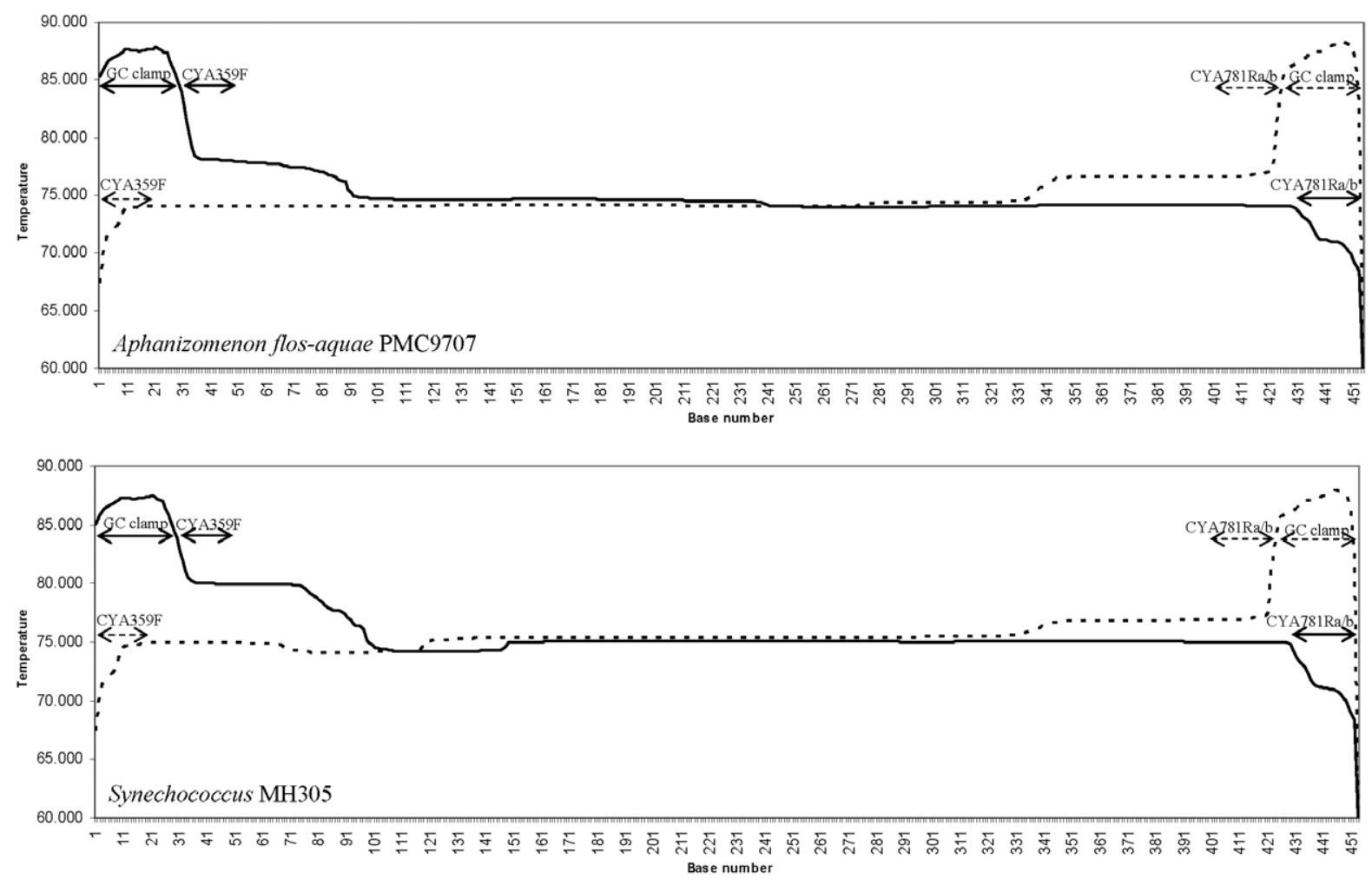

Fig. 2. Melting profiles obtained with the primer pair CYA359FGC-CYA781R(a/b), (solid line) and CYA359F-CYA781RGC(a/b) (dotted line) for sequence positions 378-781 of the 16S rRNA sequence of Aphanizomenon flos-aquae PMC9707 and for Synechococcus MH305. CYA781R(a/b) indicates CYA781R(a) or CYA781R(b) as identical profiles that were produced with primers CYA359F-CYA781R(a) and CYA359F-CYA781R(b), with the GC clamp on the forward or reverse primer. The zones corresponding to the primers and the GC clamp are indicated by an arrow.

(a) and (b). This result is supported by the DGGE patterns (Fig. 1).

In sample 0ES27, with the GC clamp on the forward primer, 10 bands (A to J) were produced in total for the separate primers instead of 6 with the combined primers (A, E, G, H, I, J, Fig. 1). With CYA359F-CYA781RG$\mathrm{C}(\mathrm{a}+\mathrm{b})$, five bands were present in the DGGE pattern $(2,4,6,7,8)$ whereas 11 bands were detected with the separate reverse primers.

Concerning sample 0ES32, 13 bands were obtained with the GC clamp on the forward primer with separate reverse primers (bands A, B, C, E, F, G, H, I, J, K, L, M, $\mathrm{N})$ while only 10 bands could be observed when the reverse primers were mixed. With the GC clamp on the reverse primer, 15 bands in total were obtained for the separate reverse primers ( 1 to 15$)$ and 6 bands $(2,5,7,8$, $9,12)$ when a combination of both primers were used.

For 0ES39 and CYA359FGC, 16 bands were thus recovered in total (A to $\mathrm{P}$ ). With the mixture of the reverse primers, 6 bands were visible. When the GC clamp was on the reverse primer, 7 bands were visible in the pattern obtained with the mixture of the reverse primers $(3,4,9,10,12,13,14)$ and 14 when the number of bands in the separate patterns were summed.

For each of the samples analysed, with the GC clamp on the forward primer, only one type of sequence was recovered with the mixture of the reverse primers. The same result was obtained with the GC clamp on the reverse primer. The sequences are related to Aphanizomenon flos-aquae PCC7905 (with the GC clamp on the forward primer) or to Synechococcus MH305 (with the GC clamp on the reverse primer) for 0ES27, to Aphanizomenon flos-aquae PMC9707 for 0ES32, and to Synechocystis PCC6803 for 0ES39.

With the separate PCR amplifications and irrespective of the position of the GC clamp, a higher number of genera was detected than with the mixture of primers according to the sequences obtained. Two (related to L. redekei CCAP 1443/1 and Synechocystis PCC6803 for 0ES39) or three (related to A. flos-aquae PMC9707, A. flos-aquae PCC7905 and Synechococcus $\mathrm{MH} 305$ for $0 \mathrm{ES} 27$ and to A. flos-aquae PMC9707, Synechococcus MH301 and Synechocystis PCC6803 for 0ES32) sequences were obtained. These 
results are congruent with the theoretical match of the reverse primers.

It is believed that, when used together, the reverse primers compete to template hybridization between them, and the genetic fingerprint obtained is thus less complete.

By making separate amplifications with the reverse primers (a) and (b), a more complete picture of the real diversity of the environmental sample can be obtained. If we consider sample $0 \mathrm{ES} 32$, four and three sequences related to the filamentous cyanobacterium A. flos-aquae were obtained with CYA359FGC-CYA781R $(\mathrm{a}+\mathrm{b})$ and CYA359F-CYA781RGC(a+b), respectively. This taxa probably dominated the environmental sample. Only when primer (b) was used alone could the unicellular populations (related to Synechococcus sp. MH301 and Synechocystis sp. PCC6803) be detected. Thus, the use of separate primers is recommended, especially when performing straightforward excisions and reamplifications of bands, where it is not always possible to obtain sequences of all bands.

\section{Conclusion}

DGGE was originally designed to detect point mutations in human genomic DNA (Sheffield et al., 1989). In medical research, detection of mutations by DGGE can be optimized by careful analysis of the melting profiles and adaptations of the primers. This is not possible when using this method for community analysis. In addition, for cyanobacteria, the primers described by Nübel et al. (1997) are the only specific primers available. The results of our study show that the banding patterns obtained with the GC clamp on the forward or on the reverse primer varies and this is due to the influence of the GC clamp position on the melting profile. Nevertheless, the number of bands observed are very similar irrespective of the position of the GC clamp. Moreover, except when using reverse primers mixed with sample $0 \mathrm{ES} 27$, the same band sequences were obtained with the GC clamp on the forward or reverse primer.

In addition, we advise to use the reverse primers CYA781R(a) and (b) separately. It gives a more complete view of the cyanobacterial community composition. The primers (a) and (b) target filamentous and unicellular cyanobacteria, respectively, and their separate use allows the two different types of populations to be revealed.

\section{Acknowledgments}

This work was funded by the European Union under the project MIDI-CHIP (EVK2-CT1999-00026) and the Belgian Federal Science Policy under the project B-
BLOOMS (EVK2/34). We thank the Public Research Center Gabriel Lippmann (Luxembourg) for collecting water samples. The authors acknowledge Denis Baurain and Arnaud Taton for managing the ARB database of cyanobacterial sequences. Thanks are due to Antoine Kremer (INRA Pierroton, France) and Xavier Vekemans (Université Libre de Bruxelles, Brussels, Belgium) for helpful advices. We thank Tony Collins for correcting the English language and anonymous reviewers for helpful comments. The reference DGGE marker was kindly provided by Pirjo Rajaniemi (University of Helsinki, Finland). A. Wilmotte is Associate Researcher of the National Fund for Scientific Research of Belgium (FNRS).

\section{Appendix A. Supplementary data}

Supplementary data associated with this article can be found, in the online version, at doi:10.1016/ j.mimet.2005.09.017.

\section{References}

Abed, R.M., Garcia-Pichel, F., Hernandez-Marine, M., 2002. Polyphasic characterization of benthic, moderately halophilic, moderately thermophilic cyanobacteria with very thin trichomes and the proposal of Halomicronema excentricum gen. nov., sp. nov. Arch. Microb. 177, 361-370.

Casamayor, E.O., Schafer, H., Baneras, L., Pedros-Alio, C., Muyzer, G., 2000. Identification of and spatio-temporal differences between microbial assemblages from two neighboring sulfurous lakes: comparison by microscopy and denaturing gradient gel electrophoresis. Appl. Environ. Microbiol. 66, 499-508.

Diez, B., Pedros-Alio, C., Marsh, T.L., Massana, R., 2001. Application of denaturing gradient gel electrophoresis (DGGE) to study the diversity of marine picoeukaryotic assemblages and comparison of DGGE with other molecular techniques. Appl. Environ. Microbiol. 67, 2942-2951.

Ercolini, D., 2004. PCR-DGGE fingerprinting: novel strategies for detection of microbes in food. J. Microbiol. Methods 56, 297-314.

Fewer, D., Friedl, T., Büdel, B., 2002. Chroococcidiopsis and heterocyst-differentiating Cyanobacteria are each other's closest living relatives. Mol. Phylogenet. Evol. 23, 82-90.

Fischer, S.G., Lerman, L.S., 1983. DNA fragments differing by single base-pair substitutions are separated in denaturing gradient gels: correspondence with melting theory. Proc. Natl. Acad. Sci. U. S. A. $80,1579-1583$.

Garcia-Pichel, F., Lopez-Cortes, A., Nubel, U., 2001. Phylogenetic and morphological diversity of cyanobacteria in soil desert crusts from the Colorado plateau. Appl. Environ. Microbiol. 67, 1902-1910.

Garcia-Pichel, F., Johnson, S.L., Youngkin, D., Belnap, J., 2003. Small-scale vertical distribution of bacterial biomass and diversity in biological soil crusts from arid lands in the Colorado plateau. Microbial. Ecol. 46, 312-321.

Geiß, U., Selig, U., Schumann, R., Steinbruch, R., Bastrop, R., Hagemann, M., Schoor, A., 2004. Investigations on cyanobacter- 
ial diversity in a shallow estuary (Southern Baltic Sea) including genes relevant to salinity resistance and iron starvation acclimation. Environ. Microbiol. 6, 377-387.

Giovannoni, S.J., DeLong, E.F., Schmidt, T.M., Pace, N.R., 1990. Tangential flow filtration and preliminary phylogenetic analysis of marine picoplankton. Appl. Environ. Microbiol. 56, 2572-2575.

Kisand, V., Wikner, J., 2003. Limited resolution of 16S rDNA DGGE caused by melting properties and closely related DNA sequences. J. Microbiol. Methods 54, 183-191.

Lerman, L.S., Silverstein, K., 1987. Computational simulation of DNA melting and its application to denaturing gradient gel electrophoresis. Methods Enzymol. 155, 482-501.

Ludwig, W., Strunk, O., Westram, R., Richter, L., Meier, H., Yadhukumar, Buchner, A., Lai, T., Steppi, S., Jobb, G., Forster, W., Brettske, I., Gerber, S., Ginhart, A.W., Gross, O., Grumann, S., Hermann, S., Jost, R., Konig, A., Liss, T., Lussmann, R., May, M., Nonhoff, B., Reichel, B., Strehlow, R., Stamatakis, A., Stuckmann, N., Vilbig, A., Lenke, M., Ludwig, T., Bode, A., Schleifer, K.-H., 2004. ARB: a software environment for sequence data. Nucleic Acids Res. 32, 1363-1371.

Lyautey, E., Lacoste, B., Ten-Hage, L., Rols, J.L., Garabetian, F., 2005. Analysis of bacterial diversity in river biofilms using $16 \mathrm{~S}$ rDNA PCR-DGGE: methodological settings and fingerprints interpretation. Water Res. 39, 380-388.

Muyzer, G., 1999. DGGE/TGGE: a method for identifying genes from natural ecosystems. Curr. Opin. Microbiol. 2, 317-422.

Myers, M.R., Fischer, S.G., Lerman, L.S., Maniatis, M., 1985. Nearly all single base substitutions in DNA fragments joined to a GCclamp can be detected by denaturing gradient gel electrophoresis. Nucleic Acids Res. 13, 3131-3145.

Nikolausz, M., Sipos, R., Revesz, S., Szekely, A., Marialigeti, K., 2005. Observation of bias associated with re-amplification of DNA isolated from denaturing gels. FEMS Microbiol. Lett. 244, 385-390.

Nollau, P., Wagener, C., 1997. Methods for detection of point mutations: performance and quality assessment. Clin. Chem. 43, $1114-1128$

Nübel, U., Garcia-Pichel, F., Muyzer, G., 1997. PCR primers to amplify 16S rRNA genes from cyanobacteria. Appl. Environ. Microb. 63, 3327-3332.
Sheffield, V.C., Cox, D.R., Lerman, L.S., Myers, R.M., 1989. Attachment of a 40-base-pair G+C-rich sequence (GC-clamp) to genomic DNA fragments by the polymerase chain reaction results in improved detection of single-base changes. Proc. Natl. Acad. Sci. U. S. A. 86, 232-236.

Sekiguchi, H., Tomioka, N., Nakahara, T., Uchiyama, H., 2001. A single band does not always represent single bacterial strains in denaturing gradient gel electrophoresis analysis. Biotechnol. Lett. 23, 1205-1208.

Speksnijder, A.G.C.L., Kowalchuk, G.A., De Jong, S., Kline, E., Stephen, J.R., Laanbroekm, H.J., 2001. Microvariation artifacts introduced by PCR and cloning of closely related 16S rRNA gene sequences. Appl. Environ. Microbiol. 67, 469-472.

Taton, A., Grubisic, S., Brambilla, E., De Wit, R., Wilmotte, A., 2003. Cyanobacterial diversity in natural and artificial microbial mats of Lake Fryxell (McMurdo Dry Valleys, Antarctica): a morphological and molecular approach. Appl. Environ. Microbiol. 69, 5157-5169.

Wilmotte, A., Demonceau, C., Goffart, A., Hecq, J.-H., Demoulin, V., Crossley, A.C., 2002. Molecular and pigment studies of the picophytoplankton in a region of the Southern Ocean $\left(42^{\circ}-54^{\circ}\right.$ S, $141^{\circ}-144^{\circ}$ E) in March 1998. Deep-Sea Res., Part 2, Top. Stud. Oceanogr. 49, 3351-3363.

Wintzingerode, F.v., Göbel, U.B., Stackebrandt, E., 1997. Determination of microbial diversity in environmental samples: pitfalls of PCR-based rRNA analysis. FEMS Microbiol. Rev. 21, $213-229$.

Wu, Y., Hayes, V.M., Osinga, J., Mulder, I.M., Looman, M.W.G., Buys, C.H.C.M., Hofstra, M.W., 1998. Improvement of fragment and primer selection for mutation detection by denaturing gradient gel electrophoresis. Nucleic Acids Res. 26, 5432-5440.

Yu, Z., Morrison, M., 2004. Comparisons of different hypervariable regions of rrs genes for use in fingerprinting of microbial communities by PCR-Denaturating Gradient Gel Electrophoresis. Appl. Environ. Microbiol. 70, 4800-4806.

Zwart, G., Kamst-van Agterveld, M.P., van der Werff-Staverman, I., Hagen, F., Hoogveld, H.L., Gons, H.J., 2005. Molecular characterization of cyanobacterial diversity in a shallow eutrophic lake. Environ. Microbiol. 7, 365-377. 